\title{
Highly active iridium(I) complexes for catalytic hydrogen isotope exchange $\dagger$
}

\author{
Jack A. Brown, ${ }^{a}$ Stephanie Irvine, ${ }^{a}$ Alan R. Kennedy ${ }^{a}$ William J. Kerr, ${ }^{* a}$ \\ Shalini Andersson ${ }^{b}$ and Göran N. Nilsson ${ }^{b}$
}

Received (in Cambridge, UK) 16th October 2007, Accepted 7th December 2007

First published as an Advance Article on the web 3rd January 2008

DOI: $10.1039 / \mathbf{b} 715938 b$

Practically convenient methods have been developed for the preparation of new iridium complexes, possessing bulky $\mathrm{N}$-heterocyclic carbene and phosphine ligands; these routinely handled complexes are highly active catalysts within directed hydrogen isotope exchange processes.

In attempts to combat high failure rates in modern drug development, the global pharmaceuticals industry has been placing increasingly greater emphasis on earlier stage metabolic studies. One of the most effective ways to follow drug metabolism is to use site-specific labelling, most conveniently with a heavy isotope of hydrogen. Within the field of hydrogen isotope exchange (HIE), the ideal situation would be to utilise sub-stoichiometric quantities of a transition metal catalyst to carry out the required transformation on a fully functionalised compound (e.g. Scheme 1), thereby avoiding any additional, time-consuming and costly, synthetic endeavours. In attempts to meet the demand for such a process, a range of platinum-, ${ }^{1}$ rhodium-, ${ }^{2}$ and iridium-based ${ }^{3}$ complexes have been applied to the area, each of which has shown varying degrees of efficacy. Perhaps the most effective complex used in this field is Crabtree's catalyst. ${ }^{4}$ However, whilst showing activity across a range of substrates, this complex is regularly required in (super-)stoichiometric amounts, and often leads to low isotope incorporation levels and undesirably lengthy reaction times. ${ }^{5}$ Further, in our experience, usage of Crabtree's catalyst in tritium exchange reactions leads to high amounts of (tritiated) waste which has environmental implications. Hence, there is a distinct requirement for a robust and catalytically viable set of metal-complex systems for use in such exchange

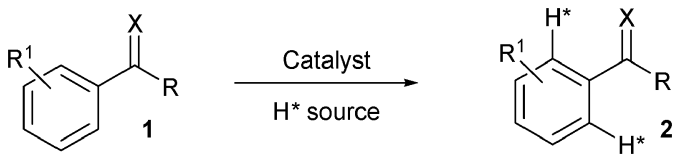

Scheme 1 Ideal hydrogen isotope exchange process.

${ }^{a}$ Department of Pure and Applied Chemistry, WestCHEM, University of Strathclyde, 295 Cathedral Street, Glasgow, Scotland, UK G1 1XL.E-mail:w.kerr@strath.ac.uk; Fax:+44 141548 4246; Tel: + 441415482959

${ }^{b}$ Medicinal Chemistry, AstraZeneca, R\&D Mölndal, SE-431 83 Mölndal, Sweden

† Electronic supplementary information (ESI) available: Experimental protocols and full characterisation data for novel compounds. See DOI: $10.1039 / \mathrm{b} 715938 \mathrm{~b}$ processes and which will label to a high degree over a range of substrates. Herein, we report our initial endeavours to develop a series of new iridium complexes which would deliver these objectives.

Nolan $^{6}$ and Buriak $^{7}$ have elegantly established that manipulation of the ligand sphere around iridium can improve both stability and catalytic activity relative to Crabtree's catalyst, albeit within the field of alkene hydrogenation. Consequently, our initial efforts focused upon the preparation of iridium complexes with greater steric demand around the metal centre. In this regard, it was felt that the specific combination of a bulky $N$-heterocyclic carbene (NHC), ${ }^{8}$ such as 1,3 -bis $(2,4,6-$ trimethylphenyl)imidazol-2-ylidene (IMes), with an appreciably encumbered phosphine, would serve to deliver robust and effective complexes for use within exchange studies.

In terms of access to the desired complexes, despite describing routes to related species, Buriak was less successful in attempts to prepare compounds possessing both a relatively bulky phosphine and a more sterically-demanding $\mathrm{NHC}^{7}$ In contrast, as part of this programme, a modification of Herrmann's procedure, for in situ generation and introduction of the NHC ligand, ${ }^{9}$ was employed to deliver a range of novel iridium complexes (Table 1). In the developed protocol, use of a relatively non-coordinating solvent such as benzene in the initial steps was found to be essential; more polar solvents (e.g. ethanol, THF, or diethyl ether) led to either difficult isolation or inefficient preparative processes. Isolation and handling of

Table 1 Preparation of iridium complexes $\mathbf{5 a}-\mathbf{e}^{a}$

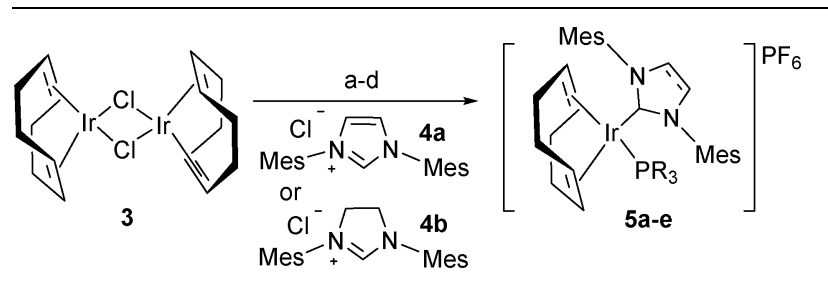

\begin{tabular}{lllll} 
Entry & Heterocycle & $\mathrm{PR}_{3}$ & Complex & Yield $(\%)^{b}$ \\
\hline 1 & $\mathbf{4 a}$ & $\mathrm{PPh}_{3}$ & $\mathbf{5 a}$ & 62 \\
2 & $\mathbf{4 a}$ & $\mathrm{PBn}_{3}$ & $\mathbf{5 b}$ & 59 \\
3 & $\mathbf{4 a}$ & $\mathrm{PMe}_{2} \mathrm{Ph}$ & $\mathbf{5 c}$ & 71 \\
4 & $\mathbf{4 b}$ & $\mathrm{P} \mathrm{Bu}_{3}$ & $\mathbf{5 d}$ & 30 \\
5 & $\mathbf{4 b}$ & $\mathrm{PPh}_{3}$ & $\mathbf{5 e}$ & 31
\end{tabular}

${ }^{a}$ Reaction conditions: (a) NaOEt, PhH, r.t., 10 min; (b) $4 \mathbf{a}$ or $\mathbf{4 b}$, $\mathrm{PhH}$, r.t., $5 \mathrm{~h}$; (c) $\mathrm{AgPF}_{6}$, THF, r.t., $30 \mathrm{~min}$; (d) $\mathrm{PR}_{3}$, THF, r.t., 2 h. ${ }^{b}$ Isolated yields. 


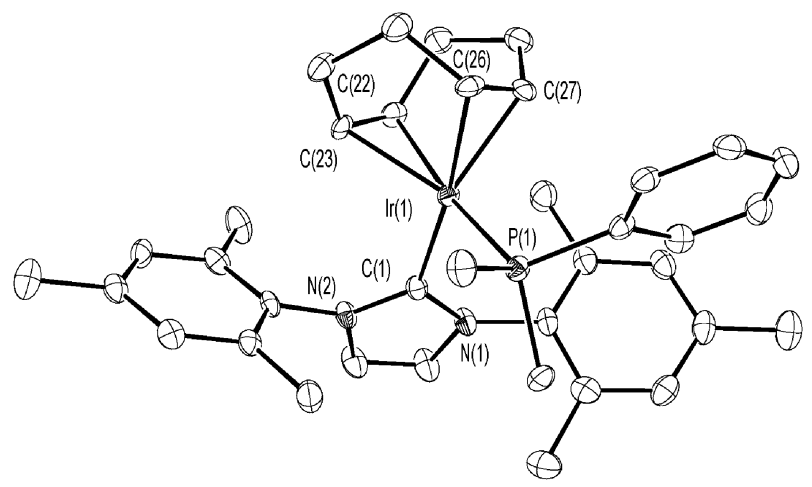

Fig. 1 Molecular structure of the cationic portion of $\mathbf{5 c}$ with displacement ellipsoids set at $50 \%$ probability. Selected bond lengths $(\AA)$; $\operatorname{Ir}(1)-\mathrm{C}(1) \quad 2.079(3), \quad \operatorname{Ir}(1)-\mathrm{P}(1) \quad 2.3239(8), \quad \operatorname{Ir}(1)-\mathrm{C}(22) \quad 2.222(3)$, $\operatorname{Ir}(1)-C(23) 2.170(3), \operatorname{Ir}(1)-C(26) 2.221(3), \operatorname{Ir}(1)-C(27) 2.167(3)$.

the carbene ligand is also avoided by the established synthetic strategy, with no glove box techniques being required. By employing this preparative method, a number of previously unreported iridium complexes were readily prepared in moderate to good yields. These complexes are all highly coloured and are air- and moisture-stable solids, which were fully characterised by NMR, mass spectral, and crystallographic techniques. $\ddagger$ The crystal structure of complex $\mathbf{5 c}$ is illustrated in Fig. 1. ${ }^{10,11}$

With the new Ir compounds in hand, their ability to catalyse the requisite HIE reactions was examined by using standard conditions of $5 \mathrm{~mol} \%$ of the Ir complex in DCM under 1 atmosphere of deuterium gas. Initially, we chose to apply substrates (6a-g) which label through a five-membered metallocyclic intermediate $(5 \mathrm{mmi})$. At only $5 \mathrm{~mol} \%$ Ir loading, high levels of deuterium incorporation were readily realised (7a-g; Table 2). Importantly, the position of incorporation was entirely predictable, completely regioselective, and reproducible. The further flexibility of the new complex systems was illustrated by the application of more demanding substrates, which label through a six-membered metallocyclic intermediate $(6 \mathrm{mmi})$. As can be seen from the final two compounds in Table 2, the simplest substrate, acetanilide, is readily labelled by the catalysts examined, and the benzanilide functionality sees efficient incorporation via both 5 and 6 mmi's. From these results, catalysts $\mathbf{5 a}-\mathbf{c}$ are clearly capable of efficiently labelling ketones, amides, heterocycles, and nitroarenes to equally high levels. Traditionally more difficult substrates such as benzamide ${ }^{3 c, d, 5}$ and $N$-phenylpyrazole ${ }^{5}$ are also readily tolerated, as is a tertiary benzamide, notably without incorporation into the $N$-ethyl units. In contrast, efficient labelling of such substrates with Crabtree's catalyst typically requires considerably higher complex loadings up to $110 \mathrm{~mol} \%{ }^{5}$ Furthermore, the success in labelling nitroarenes is particularly noteworthy, since such substrates have proved to be especially challenging, with previously employed catalysts leading to only low levels of incorporation and even reduction of the nitro unit. ${ }^{3 b, e, 5}$

In terms of the saturated NHC-containing complexes, for example, 5e showed good levels of labelling with some substrates (e.g. $99 \%$ for acetophenone and $92 \%$ for $N$-phenylpyrazole, both at $5 \mathrm{~mol} \%$ loading) but was not quite as
Table 2 HIE studies with complexes $\mathbf{5} \mathbf{a}-\mathbf{c}^{a, b}$<smiles>[2H]c1cccc([2H])c1C(C)=O</smiles>

5a: $97 \%$; 5 b: $98 \%$; 5c: $98 \%$<smiles>[2H]c1cc(C)cc([2H])c1C(=O)NCC</smiles>

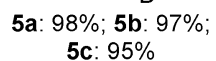<smiles>[2H]c1cccc([2H])c1[N+](=O)[O-]</smiles>

5a: $98 \%$; 5b: 97\%; 5c: $98 \%$<smiles>[2H]c1cccc([2H])c1C(=O)c1c([2H])cccc1[2H]</smiles>

5a: $95 \%$; 5 b: $96 \%$; 5c: $95 \%$<smiles>[2H]c1cccc([2H])c1-c1ccccn1</smiles>

5a: $98 \%$; 5b: 38\%; 5c: $95 \%$<smiles>[2H]c1cccc([2H])c1NC(C)=O</smiles>

5a: $94 \%$; 5b: 95\%; 5c: $91 \%$<smiles>[2H]c1cccc([2H])c1C(N)=O</smiles>

5a: $32 \% ; \mathbf{5 b}: 79 \%$; 5c: $75 \%$<smiles>[2H]c1cccc([2H])c1-n1cccn1</smiles>

5a: 96\%; 5b: 94\%; 5c: $93 \%$<smiles>[2H]c1cccc([2H])c1NC(=O)c1c([2H])cccc1[18OH]</smiles>

${ }^{a} 5 \mathrm{~mol} \%$ of Ir catalyst employed over $16 \mathrm{~h} .{ }^{b}$ Average incorporation into the positions shown over two separate reaction runs; the percentage given refers to the level of $\mathrm{D}$ incorporation over the total number of positions shown, e.g. $97 \%$ for the two possible positions in $\mathbf{7 a}$ indicates $1.94 \mathrm{D}$ incorporation.

generally effective across the full spectrum of compound types applied.

To further explore the capabilities of these catalysts, a loading study showed that excellent $\mathrm{D}$ incorporation is achievable, even with catalyst levels as low as $0.5 \mathrm{~mol} \%$ (Scheme 2). In terms of reaction time, at a loading of only $0.5 \mathrm{~mol} \%$, complex $\mathbf{5 c}$ is capable of almost complete incorporation of deuterium after only 90 minutes; $\mathbf{5 a}$ and $\mathbf{5 b}$ behaved just as effectively at the same $0.5 \mathrm{~mol} \%$ loading to firmly establish the extremely high level of catalytic activity displayed by this series of new Ir complexes.

Presently, we believe that the combination of two encumbered ligand systems is key to the observed catalytic activity of the complexes prepared as part of this programme. This may be related to two factors. Firstly, the bulky carbene and phosphine could impart greater stability upon the catalytic intermediates involved in the reaction, preventing the formation of inactive iridium clusters $^{3}$ (or promoting the existence of active Ir-based monomeric species ${ }^{7 b}$ ). Alternatively, the electron-rich and sterically crowded ligand sphere may aid both the oxidative addition and reductive elimination steps within the overall exchange mechanism. To confirm the requirement for sterically demanding ligand systems, we prepared two complexes which were reported by Buriak: ${ }^{7}$

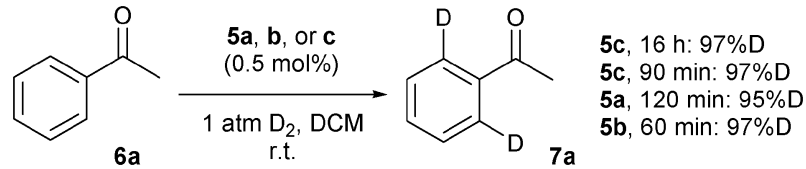

Scheme 2 Catalyst loading and labelling time study. 
(COD) $\operatorname{IrP} n \mathrm{Bu}_{3}(\mathrm{IMe}) \mathbf{8 a}$, and (COD) $\operatorname{IrP} n \mathrm{Bu}_{3}$ (IMes) 8b. When applied within attempted labelling processes with acetophenone, complex 8a, bearing the considerably less bulky IMe ligand, was completely inactive. In contrast, complex $\mathbf{8 b}$ is a competent exchange catalyst over a range of substrates. Having stated this, complex $\mathbf{8 b}$ was not as generally effective (e.g. only a $56 \% \mathrm{D}$ incorporation with 2-phenylpyridine at 5 mol\% loading) as the iridium species, 5a-c. Further studies into general ligand effects in this area are ongoing and will be reported in due course.

Finally, since benzanilides are capable of labelling through both a 5 and a $6 \mathrm{mmi}$ (see 7i., Table 2), we wondered whether the new catalyst systems could be employed to deliver selective exchange within such substrates; this would be of considerable practical use, particularly for application in pharmaceuticallybased metabolism studies. As shown in Scheme 3, complex 5c shows very high isotope incorporation via both possible metallocyclic intermediates at $5 \mathrm{~mol} \%$ loading. Pleasingly, reduction in catalyst $\mathbf{5 c}$ loading has a dramatic effect upon the level of $\mathrm{D}$ incorporation into the position (b) activated through a $6 \mathrm{mmi}$, while the position (a), labelled via a $5 \mathrm{mmi}$, sees consistently high D uptake. This study illustrates a further distinct practical advantage delivered by these novel iridium catalyst systems. To our knowledge, this level of labelling selectivity is unprecedented in the literature.
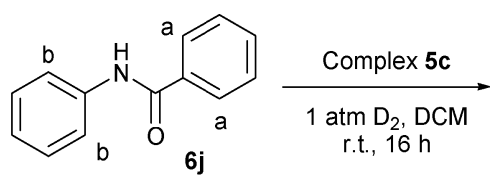

5.0 mol\%: (a) $95 \%$; (b) $93 \%$
0.5 mol\%: (a) $94 \%$; (b) $2 \%$

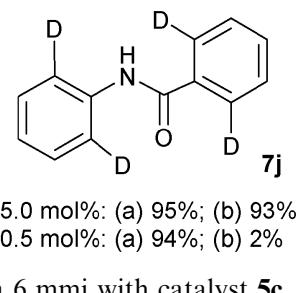

In summary, practically accessible methods for the preparation of a range of novel, robust, and readily handleable iridium(I) complexes, bearing a bulky NHC-phosphine ligand combination, have been established. These complexes have revealed catalytic activity in exchange processes far in excess of the industry standard, Crabtree's catalyst, with excellent levels of labelling being achievable over short reaction times and at extremely low metal complex loadings. The ability to perform selective labelling via a $5 \mathrm{mmi}$, over a $6 \mathrm{mmi}$, has also been shown to be possible. One further practical benefit relates to the prolonged stability of these complex species; for example, following storage under an air atmosphere at room temperature for over 8 months, complex 5c (5 mol\% loading) was shown to be significantly active in delivering 95\% D incorporation within substrate $\mathbf{6 d}$ after $16 \mathrm{~h}$ at room temperature.

We thank the University of Strathclyde for a Postgraduate Studentship (J.A.B.), AstraZeneca, R\&D Mölndal for postgraduate studentship funding (S.I.), and the EPSRC Mass Spectrometry Service, University of Wales, Swansea, for analyses.

\section{Notes and references}

$\ddagger$ CCDC 634672. For crystallographic data in CIF or other electronic format, see DOI: $10.1039 / \mathrm{b} 715938$ b

1 J. L. Garnett and R. J. Hodges, J. Am. Chem. Soc., 1967, 89, 4546.

2 (a) M. R. Blake, J. L. Garnett, I. K. Gregor, W. Hannan, K. Hoa and M. A. Long, J. Chem. Soc., Chem. Commun., 1975, 930; (b) W. J. S. Lockley, Tetrahedron Lett., 1982, 23, 3819; (c) W. J. S. Lockley, J. Labelled Compd. Radiopharm., 1984, 21, 45; (d) W. J. S. Lockley, J. Labelled Compd. Radiopharm., 1985, 22, 623; (e) D. Hesk, J. R. Jones and W. J. S. Lockley, J. Pharm. Sci., 1991, 80, 887.

3 (a) R. H. Crabtree, E. M. Holt, M. Lavin and S. M. Morehouse, Inorg. Chem., 1985, 24, 1986; (b) R. Heys, J. Chem. Soc., Chem. Commun., 1992, 680; (c) J. R. Heys, A. Y. L. Shu, S. G. Senderoff and N. M. Phillips, J. Labelled Compd. Radiopharm., 1993, 33, 431; (d) A. Y. L. Shu, W. Chen and J. R. Heys, J. Organomet. Chem., 1996, 524, 87; (e) J. G. Ellames, S. J. Gibson, J. M. Herbert, W. J. Kerr and A. H. McNeill, Tetrahedron Lett., 2001, 42, 6413; $(f)$ P. W. C. Cross, J. G. Ellames, J. S. Gibson, J. M. Herbert, W. J. Kerr, A. H. McNeill and T. W. Mathers, Tetrahedron, 2003, 59, 3349; (g) J. G. Ellames, J. S. Gibson, J. M. Herbert, W. J. Kerr and A. H. McNeill, J. Labelled Compd. Radiopharm., 2004, 47, 1; (h) M. B. Skaddan, C. M. Yung and R. G. Bergman, Org. Lett., 2004, 6, 11; (i) C. M. Yung, M. B. Skaddan and R. G. Bergman, J. Am. Chem. Soc., 2004, 126, 13033; (j) R. N. Garman, M. J. Hickey, L. P. Kingston, B. McAuley, J. R. Jones, W. J. S. Lockley, A. N. Mather and D. J. Wilkinson, J. Labelled Compd. Radiopharm., 2005, 48, 75; (k) J. Krüger, B. Manmontri and G. Fels, Eur. J. Org. Chem., 2005, 1402; (l) M. B. Skaddan and R. G. Bergman, J. Labelled Compd. Radiopharm., 2006, 49, 623.

4 (a) R. H. Crabtree, Acc. Chem. Res., 1979, 12, 331; (b) D. Hesk, P. R. Das and B. Evans, J. Labelled Compd. Radiopharm., 1995, 36, 497.

5 G. J. Ellames, J. S. Gibson, J. M. Herbert and A. H. McNeill, Tetrahedron, 2001, 57, 9487.

6 H. M. Lee, T. Jiang, E. D. Stevens and S. P. Nolan, Organometallics, 2001, 20, 1255.

7 (a) L. D. Vásquez-Serrano, B. T. Owens and J. M. Buriak, Chem. Commun., 2002, 2518; (b) L. D. Vazquez-Serrano, B. T. Owens and J. M. Buriak, Inorg. Chim. Acta, 2006, 359, 2786.

8 (a) A. J. Arduengo, III, R. L. Harlow and M. Kline, J. Am. Chem. Soc., 1991, 113, 361; (b) A. J. Arduengo, III, Acc. Chem. Res., 1999, 32, 913; (c) W. A. Herrmann and C. Köcher, Angew. Chem., Int. Ed. Engl., 1997, 36, 2162; (d) T. Westkamp, V. P. W. Bohm and W. A. Herrmann, J. Organomet. Chem., 2000, 600, 12; (e) W. A. Herrmann, Angew. Chem., Int. Ed., 2002, 41, 1290; (f) It should be noted that $\mathrm{Cp}^{*} \operatorname{Ir}(\mathrm{NHC})$ (dihalide) complexes have recently been reported and used in HIE processes under relatively forcing conditions, with $\mathrm{CD}_{3} \mathrm{OD}$ (or $\left(\mathrm{CD}_{3}\right)_{2} \mathrm{CO}$ ) as the deuterium source; see: R. Corberân, M. Sanau and E. Peris, J. Am. Chem. Soc., 2006, 128, 3974.

9 C. Kocher and W. A. Herrmann, J. Organomet. Chem., 1997, 532, 261.

10 Crystal Data for $5 \mathbf{5 c} \cdot 0.35 \mathrm{CCl}_{2} \mathrm{H}_{2} \cdot 0.3 \mathrm{H}_{2} \mathrm{O}: \mathrm{C}_{37.35} \mathrm{H}_{48.3} \mathrm{Cl}_{0.7} \mathrm{~F}_{6}$ Ir$\mathrm{N}_{2} \mathrm{O}_{0.3} \mathrm{P}_{2}$ Triclinic space group $P \overline{1}, a=11.4652(2) b=$ 13.3037(2) $c=14.1374(3) \AA, \alpha=86.555(1) \beta=67.108(1), \gamma=$ $71.527(1)^{\circ}, V=1879.25(6) \AA^{3}, T=123 \mathrm{~K}, Z=2,2 \theta_{\max }=55.08^{\circ}$, $\operatorname{MoK}_{\alpha} \lambda=0.71073 \AA$. The structure was solved and refined on $F^{2}$ (SHELXS and SHELXL-97; G. M. Sheldrick, University of Göttingen, Germany) to convergence at $R 1=0.0280$ (for 7433 reflections with $I>2 \sigma(I)) \mathrm{w} R 2=0.0528$ and $S=1.018$ for 469 parameters and 8614 unique reflections. Minimum/maximum residual electron density $-0.573 / 0.850 \mathrm{e}^{-3}$. CCDC 634672 . For crystallographic data in CIF or other electronic format, see DOI: $10.1039 / \mathrm{b} 715938 \mathrm{~b}$.

11 Following the completion of this preparative work, one of these complexes (5d) was reported in the literature, having been prepared by an alternative and more synthetically demanding route; see ref. $7 b$. 